\title{
Teaching Engineering Ethics using BLOCKS Game
}

3 Abstract The aim of this study was to investigate the use of a newly

4 developed design game called BLOCKS to stimulate awareness of ethical

5 responsibilities amongst engineering students. The design game was played by

6 seventeen teams of chemical engineering students, with each team having to

7 arrange pieces of colored paper to produce two letters each. Before the end of the

8 game, additional constraints were introduced to the teams such that they faced

9 similar ambiguity in the technical facts that the engineers involved in the

10 Challenger disaster had faced prior to the space shuttle launch. At this stage, the

11 teams had to decide whether to continue with their original design or to develop

12 alternative solutions. After the teams had made their decisions, a video of the

13 Challenger explosion was shown followed by a post-game discussion. The

14 students' opinion on five Statements on ethics was tracked via a Five-Item Likert

15 survey which was administered three times, before and after the ethical scenario

16 was introduced, and after the video and post-game discussion. The results from

17 this study indicated that the combination of the game and the real-life incident

18 from the video had generally strengthened the students' opinions of the

19 Statements.

20 Keywords Engineering ethics; design game; video; historical case-scenario

\section{Introduction}

23 The incorporation of the teaching of ethics in engineering programs has taken

24 formal forms in recent years. The importance of ethics is reflected in the 25 accreditation criteria set by ABET (2009) where Criterion 3, Program Outcomes,

26 specifically states that engineering students must be able to demonstrate "an

27 ability to design a system, component, or process to meet desired needs within

28 realistic constraints such as economic, environmental, social, political, ethical,

29 health and safety, manufacturability, and sustainability" as well as "an

30 understanding of professional and ethical responsibility". The increasing extent

31 of globalization and multidisciplinary elements in engineering projects means that 
1 engineers today are faced with a number of ethical considerations that extend

2 beyond what they can learn from textbooks. In addition, recent high profile

3 engineering failures, such as the recent Deepwater Horizon oil spills, are constant

4 reminders of the impact of engineering disasters on society at large.

5 Teaching of engineering ethics may encompass four increasingly difficult goals

6 of (i) raising ethical sensitivity, (ii) adding to ethical knowledge, (iii) improving

7 ethical judgment and (iv) increasing ethical willpower (Riley et al. 2009). A

8 range of programs has been taken to achieve one or more of these goals, ranging

9 from brief discussions of professional responsibility and ethics, to modules which

10 consist of two or three class sessions, to full blown ethics course that involves

11 assessments such as quizzes, exams and assignments (Colby and Sullivan 2008;

12 Rabins 1998).

13 In terms of pedagogical methods, various methods of teaching ethics have also

14 been attempted, consisting of lectures, case studies as well as software-based

15 simulators (e.g. Chung and Alfred 2009). The most popular method which has

16 been claimed to have an immediate impact on students (Cruz and Frey 2003) is

17 the use of case studies. A vast number of ethical case studies is available in the

18 literature for use in the classroom. For example, the Center for the Study of

19 Ethics in Society at Western Michigan University has compiled a number of case

20 studies that can be used to stimulate reflection on ethical issues from different

21 perspectives (Pritchard 1992). Each case study may be further presented in

22 various formats such as simple discussion, workshops, simulations and games

23 (e.g. Cruz and Frey 2003; Fleddermann 2000; Kline 2001; Lewis et al. 2010;

24 Pritchard 1992; van der Burg and van de Poel 2005). Riley and co-workers

25 (2009) described a "low-dose" approach where typical engineering problems that

26 require routine calculations are reformulated to include decision making that

27 entails elements of ethical considerations. Historical events have also been used

28 to teach ethics, such as the efforts of Billington (2006), Bowyer (2001) and Kline 29 (2001).

30 The motivation behind this study is to investigate the use of games to stimulate 31 awareness of ethical responsibilities amongst engineering students. Games

32 provide a way of getting students to use their practical knowledge in managing

33 indeterminate, open-ended situations within a rule-bound, social and competitive

34 environment (Lloyd and van de Poel 2008). In games, students actively 
1 participate in problems in a fun manner and this is thought to result in a higher 2 efficiency of learning (Haywood et al. 2004).

3 The idea by Lloyd and van de Poel (2008) to couple an ethical case-scenario 4 with design games in the teaching of ethics was adopted in this study. Lloyd and 5 van de Poel (2008) used the Delta Design ${ }^{1}$ game (Bucciarelli 1999) which was 6 developed specifically for engineering students. The game is based around a team 7 of four members collaborating to design a residence on a fictional planet called 8 DeltaP. Lloyd and van de Poel (2008) introduced an explicit ethical scenario in 9 the game by assuming that a "gravity wave" had occurred which destroyed 10 buildings and caused a loss of life. Students then had to review the design and 11 consider the ethical issues that arose during the design process.

12 Instead of Delta Design, the game used in the current study was newly 13 developed to contain design elements yet sufficiently simple to be played by 14 students of non-engineering background. The ethical scenario was introduced 15 before the end of the game such that the students had to make decisions on their 16 design based on limited information. Once the students had arrived at a decision, 17 a video clip of the Challenger space shuttle explosion disaster was shown. The use 18 of circumstantial conditions based on a real-life engineering disaster follows the 19 work by Kuhn (1998), where students were given a simulation that is modelled on 20 the circumstances surrounding the Challenger launch. In Kuhn's (1998) work, the 21 simulation was disguised as a case in which decision has to be made on the use of 22 an engine which has an undetermined trouble with new O-rings. After the 23 students had made the decision they were shown a video clip of the Challenger 24 explosion. A recent simulation by Kroesen and van der Zwaag (2010) has also 25 attempted to mimic the circumstances surrounding the Challenger explosion.

26 The link between a fictitious design game and real-life events in the current 27 study was expected to provide more impact on learning (such as the 'shock' that is 28 described in Kuhn (1998)) compared to just having a fictitious disaster in the 29 game (such as that used in Lloyd and van de Poel (2008)). Whereas previous 30 studies by Kroesen and van der Zwaag (2010), Kuhn (1998), and Lloyd and van 31 de Poel (2008) did not involve an evaluation of the students' learning, in the 32 current study, we attempted to evaluate the effectiveness of the game to increase

\footnotetext{
${ }^{1}$ http://ocw.mit.edu/courses/civil-and-environmental-engineering/1-101-introduction-to-civil-andenvironmental-engineering-design-i-fall-2006/delta-game/. Accessed 3 August 2011.
} 
1 awareness in ethics by measuring students' responses at different stages of the

2 game (such as in Loui (2006)).

\section{Methodology}

5 The game was played by Year 2 and Year 3 chemical engineering students

6 during the Chemical Engineering Day which is an annual event held at Curtin

7 University, Sarawak, Malaysia. Eighty percent of the students were Malaysians

8 while the rest were non-Malaysians. Eighty-one percent of the Year 2 students

9 and ninety percent of the Year 3 students had completed a Year 1 Engineering

10 Foundation Design and Processes unit which incorporates a lecture on ethics in a

11 single class session. For the Year 3 students, seventy-five percent had also prior

12 exposure to ethical related issues in social, environmental and economic aspects

13 through a Year 3 unit called Engineering Sustainable Development.

\section{Game Concept}

16 The game developed was called 'BLOCKS' and was based on the concept of 17 constraint satisfaction, where the students had to arrange pieces of colored paper 18 according to a set of constraints. A correct arrangement was considered a valid 19 'design solution'. The constraints were developed such that each team had to 20 produce two letters and when the solutions of all teams were combined, the words 21 "CHEMICAL ENGINEERING" would be formed. Thus, each team had a 22 different set of constraints to produce a different solution. The teams were not 23 told of the letters and the constraints were disguised as a design problem. An 24 example set of constraints, to produce the letters " $\mathrm{CH}$ " as shown in Fig. 1, is as 25 follows:

26 1) ' $L$ ' shape on the top left corner. The two blocks that form the ' $L$ ' must 27 touch.

28 2) The bottom half shape mirrors the top half shape.

29 3) Fold a block in half. This block must be between red and green.

30 4) Total of 9 blocks required.

31 5) Big parking space on West area. Have a clear space of $40 \times 40 \mathrm{~km}^{2}$.

32 6) Red block must be at least $20 \mathrm{~km}$ away from other red blocks. 
7) Green blocks must be exactly $5 \mathrm{~km}$ from red blocks.

2 8) Red blocks must be on the north side of green blocks.

3 9) One blue block on the South side. This blue block's short end faces EastWest direction.

5 10) No yellow blocks allowed.
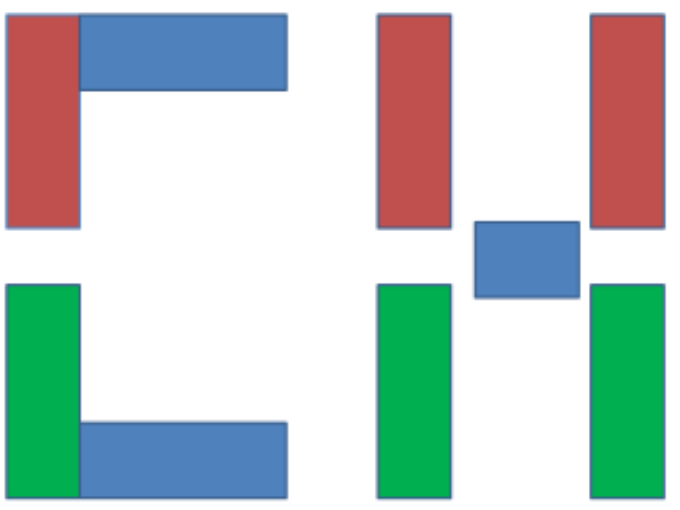

8 Fig. 1 Example solution to a set of constraints for an individual team

10 Game Project Scenario

11 The students were divided into seventeen teams. Each team had to elect a

12 Project Manager and a Lead Engineer while the rest of the team members carried 13 the role as Engineers. Each team was given a project briefing (Fig. 2). The one 14 page briefing document includes the fictional scenario, game rules and the time 15 limit which was sixty minutes. In addition, the Board of Engineers Malaysia's 16 Code of Professional Conduct was also provided to each student.

Your group is a member of the ACME Company. ACME designs and builds chemical plants. After many years of research and a huge amount of funding injected by the government as well as delays in developing the technology, ACME has developed the BLOCKS design technology which simplifies the design of complex system. ACME has successfully designed and built chemical plants in major cities in Malaysia.

ACME is bidding for major contracts from around the world to build the world's most advanced chemical plants. The first bidding will take place in Europe. If ACME is successful in its bid, it will have evidence to convince other interested countries to invest in its technology and to realize Malaysia's ambitious plans to be an international player. Failure to win will mean that 
all the money that the country has put into has gone to waste as the product does not meet international scrutiny.

Your group is tasked to design and submit the final design to the European Union at a conference in Europe. The submission will be made by the CEO of ACME to government officials, appointed engineers and scientists from the EU, ACME's competitors and international media at 11.00 am sharp at LTBS II room.

ACME's CEO has every confidence that you will be successful in this mission. The Prime Minister of Malaysia, who is currently visiting the same country where the conference is held, is also banking on ACME's potential success before he makes his speech on innovation in Malaysia. Good luck.

Your group's task is to arrange the blocks (colored paper) on the mahjong paper in a way that satisfies all constraints.

The constraints are in the envelope given. Each member of your team will have 1-2 constraints. You are not allowed to show your constraints to another. You are also not allowed to talk or write to each other.

Your design is complete if each of your team members agrees that the solution satisfies his/her constraints. The final design is one in which all required blocks are taped onto the paper.

No matter what, you must not be late for the 11.00 am conference.

\section{IF YOU DO NOT SATISFY ALL CONSTRAINTS OR ARE LATE FOR SUBMISSION,} YOU FAIL THE GAME.

Fig. 2 The project briefing that was given to all teams

Game Rules

27 Each team was given ten pieces of colored paper and one piece of butchers 28 paper. Each team member was given one or two constraints, for example: "Red 29 block is always $2 \mathrm{~km}$ West of the Blue block" and "One Yellow block must touch 30 two Red Block". The other group members had different constraints. The group 31 must arrange the colored papers or blocks in a way that satisfies all the constraints 32 held by group members. To increase the difficulty of the problem, each team was 33 provided either with resource scarcity ("We don't have enough reds") or 34 abundance ("We don't need this many yellows"). Initially, the team members were not allowed to talk nor show their constraints to each other, but these

36 constraints were removed one after another during the game. Following this, the 37 teams were allowed to request or trade with other teams. 
2 Ethical Scenario

3 The ethical scenario was set up to create two divergent roles within a team that

4 must collectively decide before time runs out. At ten minutes before the end of

5 the time limit, the facilitators announced that

6 "On the day of bidding, the location where the chemical plant will be built

7 experienced an unusually low temperature with record amount of snow.

8 The design specifications had specified a temperature range from $10^{\circ} \mathrm{C}$

9 onwards, but on that day, the temperature was $-5^{\circ} \mathrm{C}$. The low temperature

10 was exceptional, but just before your submission, the panel of engineers and

11 scientists had wanted reassurance that your design would be safe to operate

12 under the exceptional weather as has been happening."

14 The Project Manager for each team was called for a briefing and given an 15 email from the company CEO (Fig. 3).

\section{From: CEO}

To: Project Management Department

This project is the life and death of ACME Corporation. No matter what, make sure that engineering gets the design to be submitted to the client. If you do not submit, there will be a loss of reputation and the nation will also not be happy that no successful outcome has come out from the years of funding.

There have been some rumblings from concerned engineers. Unless there is a clear and

Fig. 3 Email from CEO to Project Manager

The purpose of the email was to provide pressure on the Project Manager to continue with the project launch for the sake of the Project Manager, company and nation. After the Project Managers were dismissed, the Lead Engineer from

32 each team was called for a briefing and given an email from the company's Design 33 Engineer (Fig. 4). 


\section{From: Design Engineer}

To: Lead Engineer

So far, BLOCKS technology has proven successful in warm climate countries. We have data up to $5^{\circ} \mathrm{C}$ which show some considerable scatter but seem to indicate that the design will still work up to $5^{\circ} \mathrm{C}$. The data also show that as temperature is reduced, there is a tendency for the reaction to slow down. This retardation might cause a blockage in pipes A1242 and BS220. However, we do not have data at temperatures as low as $-5^{\circ} \mathrm{C}$ to show that the retardation will indeed cause a blockage in the pipes at those temperatures.

Fig. 4 Email from Design Engineer to Lead Engineer

This email highlighted the uncertainty of the technology if implemented outside tested parameters and its implied risks. The Lead Engineer was supposed to consider the possible failure due to technical uncertainty and to decide accordingly while the Engineers were expected to approach the decision making process under 'less pressure' compared to the Project Manager and Lead 18 Engineer.

19 Both the Project Manager and Lead Engineer were provided three options:

20 1) To submit the design as is

21 2) To withdraw the design

3) To make major changes to the design by placing red blocks exactly $1 \mathrm{~km}$ away from the green blocks.

The teams needed to make a decision within a short period of time with two opposing viewpoints and face the in-game risks of their jobs, the project's success as well as the company and nation's reputation. The option to submit the design

27 without changes meant a potentially dangerous blockage is not resolved which 28 poses the ethical dilemma. As for the third option, realistically the team would 29 not be able to submit a modified design by the deadline.

30 After the teams had submitted their decisions, the facilitators ran a short 31 debrief. Each student was asked to reflect on stakeholder communication, inter32 team cooperation and the ethical scenario. The teams were also encouraged to 33 share how and why they arrived at their decision: either to submit, withdraw or 34 make major changes. A short video on the "Space Shuttle Challenger Disaster" as 
1 found on Youtube $^{2}$ was then screened. The facilitators led a discussion on the

2 video and its relevance to the game. The facilitators highlighted that the fictional

3 game's ethical scenario was deliberately designed to mimic the real life ethical

4 scenario that the NASA engineers faced prior to the space shuttle launch.

\section{Survey and Analysis}

7 A Five-Item Likert questionnaire was administered three times to the students 8 in the following sequence, labelled as:

9 Round 1: after the initial design was finalized and before the ethical scenario was introduced

these Rounds. Four of the Statements used in Loui (2006) were included in the questionnaire for the same reasons as described by Loui (2006). For example, it was expected that while initially the students would tend to agree that they should

19 students would realize that engineers have also important responsibilities to the 20 public. In addition, it was also expected that the game would reveal that ethical 21 considerations are relevant when technical decisions are made. The fifth 22 Statement was motivated by Lloyd and van de Poel's (2008) observation that 23 ethical issues were more closely discussed after their ethical scenario was 24 presented, but not necessarily during the design process itself.

25 In this study, contingency tables were used to record and analyse the 26 relationships between the Rounds of survey and the responses to the Statements 27 using SPSS Statistics 17.0. The significance of difference between any two 28 proportions was assessed using the likelihood-ratio chi-square tests.

\footnotetext{
${ }^{2}$ http://www.youtube.com/watch?v=j4JOjcDFtBE. Accessed 12 August 2011.
} 


\section{$1 \quad$ Results}

2 Fig. 5 shows a team of the students playing the game while Tables 1 and 2 3 summarize the responses of the students. Although a total of eighty-eight students

4 participated in the game, only eighty-one completed questionnaires were obtained 5 in Rounds 1 and 2, and eighty completed questionnaires were obtained in Round

63 . A few open comments were recorded in the first questionnaire and no 7 comments were recorded in subsequent questionnaires. After the ethical scenario 8 was introduced, six teams submitted their original designs, two teams withdrew 9 and the other nine teams submitted modified designs. However, all the teams who 10 modified their designs did not manage to submit on time and required an 11 extension of the deadline.

12

13

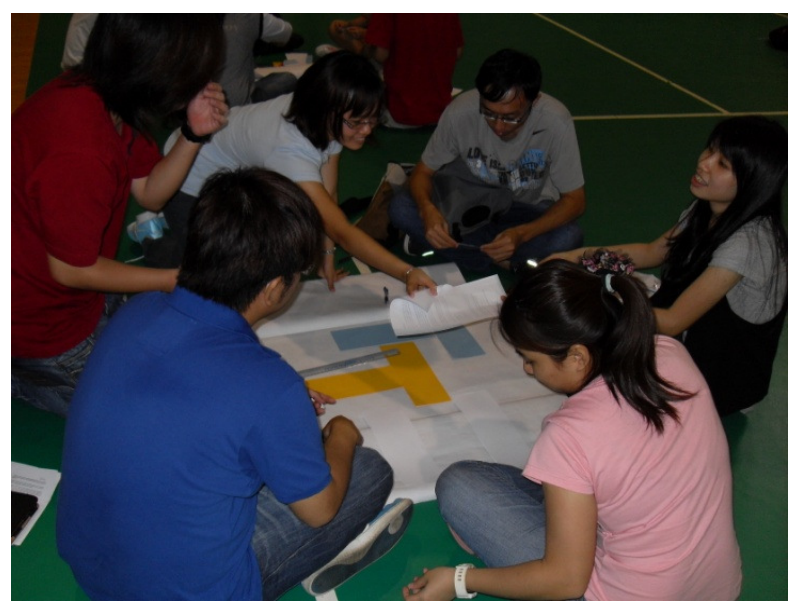

14 Fig. 5 Students participating in the BLOCKS game 
1 Table 1 Responses in the three Rounds of survey for different years of study

\begin{tabular}{|c|c|c|c|c|c|c|c|}
\hline \multicolumn{8}{|c|}{$\begin{array}{l}\text { Statement 1: The first obligation of an engineer is to fulfill an assignment from the employer, or } \\
\text { a contract with a client. }\end{array}$} \\
\hline Year & $\begin{array}{l}\text { Round of } \\
\text { Survey }\end{array}$ & $\mathrm{SA}^{*}$ & A & $\mathrm{N}$ & DA & SD & Total \\
\hline \multirow{3}{*}{2} & 1 & 16 & 19 & 5 & 1 & 0 & 41 \\
\hline & 2 & 14 & 22 & 4 & 2 & 0 & 42 \\
\hline & 3 & 15 & 14 & 7 & 4 & 0 & 40 \\
\hline \multirow{3}{*}{3} & 1 & 14 & 23 & 2 & 0 & 1 & 40 \\
\hline & 2 & 19 & 17 & 3 & 0 & 0 & 39 \\
\hline & $3^{a, b}$ & 26 & 10 & 1 & 3 & 0 & 40 \\
\hline \multicolumn{8}{|c|}{ Statement 2: Ethical considerations are an integral part of making engineering decisions. } \\
\hline Year & $\begin{array}{l}\text { Round of } \\
\text { Survey }\end{array}$ & SA & A & $\mathrm{N}$ & DA & SD & Total \\
\hline \multirow{3}{*}{2} & 1 & 17 & 22 & 2 & 0 & 0 & 41 \\
\hline & 2 & 18 & 20 & 4 & 0 & 0 & 42 \\
\hline & $3^{a, b}$ & 28 & 11 & 1 & 0 & 0 & 40 \\
\hline \multirow{3}{*}{3} & 1 & 10 & 27 & 2 & 0 & 1 & 40 \\
\hline & 2 & 16 & 22 & 1 & 0 & 0 & 39 \\
\hline & $3^{a}$ & 24 & 14 & 2 & 0 & 0 & 40 \\
\hline
\end{tabular}

Statement 3: A code of professional conduct can provide guidance in making engineering decisions.

\begin{tabular}{c|ccccccc}
\hline Year & $\begin{array}{c}\text { Round of } \\
\text { Survey }\end{array}$ & SA & A & N & DA & SD & Total \\
\hline \multirow{3}{*}{2} & 1 & 13 & 21 & 5 & 2 & 0 & 41 \\
& 2 & 18 & 21 & 3 & 0 & 0 & 42 \\
& 3 & 21 & 15 & 4 & 0 & 0 & 40 \\
\hline \multirow{3}{*}{3} & 1 & 15 & 22 & 2 & 0 & 1 & 40 \\
& 2 & 16 & 18 & 4 & 1 & 0 & 39 \\
& 3 & 23 & 12 & 4 & 1 & 0 & 40 \\
\hline
\end{tabular}

\begin{tabular}{c|ccccccc}
\hline Statement 4: Many ethical problems encountered by engineers have technical solutions. \\
\hline \multirow{2}{*}{ Year } & $\begin{array}{c}\text { Round of } \\
\text { Survey }\end{array}$ & SA & A & N & DA & SD & Total \\
\hline \multirow{3}{*}{2} & 1 & 2 & 22 & 10 & 5 & 1 & 40 \\
& 2 & 7 & 21 & 8 & 4 & 2 & 42 \\
& $3^{a}$ & 15 & 14 & 5 & 4 & 2 & 40 \\
\hline \multirow{3}{*}{3} & 1 & 4 & 19 & 13 & 3 & 1 & 40 \\
& 2 & 8 & 16 & 10 & 5 & 0 & 39 \\
& $3^{a}$ & 15 & 12 & 8 & 5 & 0 & 40 \\
\hline
\end{tabular}

Statement 5: External factors cause ethical problems, not factors resulting from the design process.

\begin{tabular}{c|ccccccc}
\hline Year & $\begin{array}{c}\text { Round of } \\
\text { Survey }\end{array}$ & SA & A & N & DA & SD & Total \\
\hline \multirow{3}{*}{2} & 1 & 4 & 23 & 10 & 3 & 1 & 41 \\
& 2 & 11 & 17 & 8 & 4 & 2 & 42 \\
& $3^{a}$ & 15 & 13 & 5 & 2 & 5 & 40 \\
\hline \multirow{3}{*}{3} & 1 & 4 & 20 & 12 & 3 & 1 & 40 \\
& 2 & 6 & 19 & 12 & 2 & 0 & 39 \\
& $3^{a}$ & 15 & 12 & 12 & 1 & 0 & 40 \\
\hline
\end{tabular}

$5 b$ Values in italics indicate significant differences between Rounds 2 and $3(p<0.05)$. 
1 Table 2 Responses in the three Rounds of survey for different roles in the game

\begin{tabular}{c|ccccccc}
\hline $\begin{array}{l}\text { Statement 1: The first obligation of an engineer is to fulfill an assignment from the employer, or } \\
\text { a contract with a client. }\end{array}$ & $\begin{array}{c}\text { Round of } \\
\text { Survey }\end{array}$ & SA $^{*}$ & A & N & DA & SD & Total \\
\hline \multirow{2}{*}{ Role } & 1 & 4 & 9 & 3 & 0 & 0 & 16 \\
Managect & 2 & 6 & 4 & 4 & 1 & 0 & 15 \\
& 3 & 4 & 4 & 3 & 2 & 0 & 13 \\
\hline \multirow{2}{*}{ Lead } & 1 & 4 & 8 & 1 & 1 & 0 & 14 \\
Engineer & 2 & 3 & 9 & 3 & 1 & 0 & 16 \\
& 3 & 6 & 5 & 1 & 2 & 0 & 14 \\
\hline \multirow{3}{*}{ Engineer } & 1 & 22 & 29 & 3 & 0 & 1 & 55 \\
& 2 & 24 & 27 & 0 & 0 & 0 & 51 \\
\hline
\end{tabular}

Statement 2: Ethical considerations are an integral part of making engineering decisions.

\begin{tabular}{c|ccccccc}
\hline Role & $\begin{array}{c}\text { Round of } \\
\text { Survey }\end{array}$ & SA & A & N & DA & SD & Total \\
\hline \multirow{2}{*}{ Project } & 1 & 7 & 7 & 2 & 0 & 0 & 16 \\
Manager & 2 & 8 & 5 & 2 & 0 & 0 & 15 \\
& 3 & 10 & 2 & 1 & 0 & 0 & 13 \\
\hline \multirow{2}{*}{ Lead } & 1 & 5 & 8 & 1 & 0 & 0 & 14 \\
Engineer & 2 & 5 & 11 & 0 & 0 & 0 & 16 \\
& 3 & 7 & 7 & 0 & 0 & 0 & 14 \\
\hline \multirow{3}{*}{ Engineer } & 1 & 16 & 36 & 2 & 0 & 1 & 55 \\
& 2 & 20 & 28 & 3 & 0 & 0 & 51 \\
& $3^{a, b}$ & 34 & 14 & 2 & 0 & 0 & 50 \\
\hline
\end{tabular}

Statement 3: A code of professional conduct can provide guidance in making engineering decisions.

\begin{tabular}{|c|c|c|c|c|c|c|c|}
\hline Role & $\begin{array}{l}\text { Round of } \\
\text { Survey }\end{array}$ & SA & A & $\mathrm{N}$ & DA & SD & Total \\
\hline \multirow{3}{*}{$\begin{array}{l}\text { Project } \\
\text { Manager }\end{array}$} & 1 & 13 & 3 & 0 & 0 & 0 & 16 \\
\hline & 2 & 9 & 5 & 0 & 1 & 0 & 15 \\
\hline & 3 & 8 & 4 & 0 & 1 & 0 & 13 \\
\hline \multirow{3}{*}{$\begin{array}{c}\text { Lead } \\
\text { Engineer }\end{array}$} & 1 & 4 & 9 & 1 & 0 & 0 & 14 \\
\hline & 2 & 7 & 8 & 1 & 0 & 0 & 16 \\
\hline & 3 & 7 & 5 & 2 & 0 & 0 & 14 \\
\hline \multirow{3}{*}{ Engineer } & 1 & 14 & 34 & 4 & 2 & 1 & 55 \\
\hline & 2 & 19 & 26 & 6 & 0 & 0 & 51 \\
\hline & $3^{a}$ & 28 & 17 & 5 & 0 & 0 & 50 \\
\hline \multicolumn{8}{|c|}{ Statement 4: Many ethical problems encountered by engineers have technical solutions. } \\
\hline Role & $\begin{array}{c}\text { Round of } \\
\text { Survey }\end{array}$ & SA & A & $\mathrm{N}$ & DA & $\mathrm{SD}$ & Total \\
\hline \multirow{3}{*}{$\begin{array}{l}\text { Project } \\
\text { Manager }\end{array}$} & 1 & 1 & 6 & 6 & 3 & 0 & 16 \\
\hline & 2 & 2 & 6 & 5 & 2 & 0 & 15 \\
\hline & 3 & 4 & 5 & 2 & 2 & 0 & 13 \\
\hline \multirow{3}{*}{$\begin{array}{c}\text { Lead } \\
\text { Engineer }\end{array}$} & 1 & 1 & 8 & 3 & 2 & 0 & 14 \\
\hline & 2 & 3 & 8 & 2 & 2 & 1 & 16 \\
\hline & 3 & 4 & 6 & 3 & 0 & 1 & 14 \\
\hline
\end{tabular}




\begin{tabular}{c|ccccccc}
\hline \multirow{3}{*}{ Engineer } & 1 & 5 & 30 & 14 & 4 & 1 & 54 \\
& 2 & 10 & 25 & 11 & 5 & 0 & 51 \\
& $3^{a, b}$ & 22 & 14 & 8 & 6 & 0 & 50 \\
\hline
\end{tabular}

Statement 5: External factors cause ethical problems, not factors resulting from the design process.

\begin{tabular}{c|ccccccc}
\hline Role & $\begin{array}{c}\text { Round of } \\
\text { Survey }\end{array}$ & SA & A & N & DA & SD & Total \\
\hline \multirow{2}{*}{ Project } & 1 & 1 & 5 & 5 & 4 & 1 & 16 \\
Manager & 2 & 6 & 5 & 3 & 1 & 0 & 15 \\
& 3 & 5 & 5 & 2 & 1 & 0 & 13 \\
\hline \multirow{2}{*}{ Lead } & 1 & 1 & 9 & 3 & 1 & 0 & 14 \\
Engineer & 2 & 2 & 7 & 5 & 1 & 1 & 16 \\
& 3 & 5 & 5 & 3 & 0 & 1 & 14 \\
\hline \multirow{3}{*}{ Engineer } & 1 & 6 & 30 & 15 & 2 & 2 & 55 \\
& 2 & 10 & 24 & 12 & 4 & 1 & 51 \\
& $3^{a}$ & 18 & 15 & 11 & 2 & 4 & 50 \\
\hline
\end{tabular}

Statement 1: The first obligation of an engineer is to fulfill an assignment 7 from the employer, or a contract with a client.

8 There were significant differences between Rounds 1 and 3, and Rounds 2 and

93 , for the Year 3 students, with an increase in the count for 'Strongly Agree' and a

10 slight increase in 'Disagree' for Round 3. The 'Neutral' count also decreased.

11 For the Year 2 students, there was no statistically significant difference between

12 the Rounds of questionnaire. However, it could be seen that the count for 'Agree'

13 decreased and was accompanied by an increase in 'Neutral' and 'Disagree' for

14 Round 3. A significant change was also found for the Engineers in the game

15 which recorded a large decrease in 'Agree' for Round 3 with a corresponding

16 increase in counts for 'Strongly Agree', 'Neutral' and 'Disagree'.

17 Students who agreed with the Statement gave the following reasons:

18 So as to achieve his goal

19 Satisfying the client's requirement is the most important task

20 Because that is the main reason we are hired as an engineer

$21 \quad$ Contract with a client

22 An engineer is to fulfil whatever their clients require in the contract. 23 Engineer's role is to come out with a design that suits their customers' 24 requirements 
Because it is an obligation

Because the clients are the ones who provide you with the assignment

Because at the end of the day is that they are paying your pay check

Students who indicated hesitation on this Statement gave the following reasons:

Agree but not totally. Some of the clients' requirement may not satisfy the safety and it's the engineers' responsibility to change the design. Take Chernobyl as example

Engineers have to fulfil assignment but ethical aspects is the number 1 factor to be considered as it concerns people's safety and life

The consideration of an engineer is equally important

Have to meet different requirements and constraints

Sometimes conflicts might happen

It depends on the professional ethics, which have been practiced in engineering

No open comments were recorded by those who disagreed with this Statement.

\section{Statement 2: Ethical considerations are an integral part of making engineering decisions.}

There were significant changes between Rounds 1 and 3 for both the Year 2 and Year 3 students. A large shift from 'Agree' to 'Strongly Agree' was observed while the counts for 'Neutral' or disagreement remained low. This shift was also significant between Rounds 2 and 3 for the Year 2 students. In fact, this Statement recorded the highest count for 'Strongly Agree' amongst all Statements for Round 3.

There were significant differences between Rounds 1 and 3, and Rounds 2 and 3, for the Engineers. The Lead Engineers appeared to show the least sensitivity to this Statement, with counts for 'Agree' and 'Strongly Agree' not changing much. Students who agreed with the Statement gave the following reasons:

Put ethical considerations on top of all. Once we disobey, there are huge consequences we have to bear. This affects environment and living. Take Chernobyl as example

Safety and environmental issues should be the main priority

Only with limits we know the objective of a project 


$$
\text { If we do not consider ethical we will not have a world to live in }
$$

Our decisions affect the public

Every design that engineers come out must meet the basic safety standard to ensure it is safe to the community and environment

If no ethical considerations, there won't be any responsibility taken before, during and after the project

No open comments were recorded by those who disagreed with this Statement.

\section{Statement 3: A code of professional conduct can provide guidance in making} engineering decisions.

Relatively high counts for 'Strongly Agree' were recorded in all Rounds of survey, across both the Year 2 and Year 3 students. There were moderate counts for 'Neutral' which did not show large changes. On the other hand there was a significant difference between Rounds 1 and 3 for the Engineers, with an increase in 'Strongly Agree' and a decrease in 'Agree'. The count for 'Strongly Agree' appeared to decrease monotonically for the Project Managers, and is the only measure across the study where this trend was observed although the decrease was not found to be statistically significant. Students who agreed with the Statement gave the following reasons:

The professional conduct helps us make decision better, in case we lack rationality

To bring out the best outcome

Provide a rule or guidance to how an engineer should think

We know what is right and wrong

No open comments were recorded by those who disagreed with this Statement.

Statement 4: Many ethical problems encountered by engineers have technical solutions and Statement 5: External factors cause ethical problems, not factors resulting from the design process.

There were significant differences between Rounds 1 and 3 for both the Year 2 and 3 students. Both Statements had relatively high 'Neutral' responses and relatively high 'Disagree' and 'Strongly Disagree' counts at Round 1, suggesting that the students were less decisive in these Statements as compared to Statements 1, 2 and 3. Both Statements recorded an increase in 'Strongly Agree' at 
1 subsequent Rounds, but for Statement 5, the Year 2 students gave an increased

2 'Strongly Disagree' response in Round 3, with the shift seemingly coming from

3 the Engineers. However, such a trend was not seen in the Year 3 students. For

4 both Statements, there were significant differences between Rounds 1 and 3 for

5 the Engineers. Although not statistically significant, there was an increase in

6 'Strongly Agree' count for Statement 5 amongst the Project Managers at Round 2,

7 and this increase was also associated with a decrease in counts for 'Neutral',

8 'Disagree' and 'Strongly Disagree' while the count for 'Agree' remained constant.

9 Students who agreed with Statement 4 gave the following reasons:

10 That's what engineers are for. We learn science and technical stuff to

11 reduce and overcome ethical issues

12 Only when the problems are identified

13 while students who disagreed with the Statement gave the following reasons:

$14 \quad$ I don't think there is any ethical problem with engineering

15 It's not the technical part that solve the problem, but the integrity of a 16 person

17 For Statement 5, students who agreed gave the following reasons:

18 External factors such as human contrasts are sometimes the root of design 19 failure

Certain factors such as economical optimization can cause ethical problems

21 while students who indicated hesitation or disagreed gave the following reasons:

Not necessarily. Sometimes

All factors must be considered

Discussion

26 The use of games to teach ethics has been suggested to offer additional benefits

27 compared with the conventional case method analysis which may engage the

28 students' intellect but does not necessarily involve students emotionally in a way

29 that enhances reasoning and allows for the examination of personal ethical

30 strengths (Kuhn 1998). Further adaptation of games to the teaching of ethics has

31 been made through the coupling of case-scenario to the games. One example is

32 the Delta Design game (Bucciarelli 1999), which was initially developed as a 
1 design game and was then adapted by Lloyd and van de Poel's (2008) by injecting

2 an ethical dilemma based on the design parameters of the game.

3 The current study drew heavily on the approach of these researchers, insofar as

4 an ethical scenario, based on key parameters that surround a real-life disaster, was

5 superimposed on a design game. The game itself was newly-developed and

6 contained a number of elements that may be used to teach different aspects of

7 ethical and professional skills such as inter- and intra-team communication,

8 negotiation and leadership. For example, each team member could have a

9 different constraint which was not to be revealed to other team members. This

10 no-talk rule could be used to simulate the situation where stakeholders do not

11 overtly share their requirements. The no-talk rule can then be removed to show

12 how the design phase is different when stakeholders clearly communicate the

13 requirements. As different teams have different sets of constraints, each team has

14 to trade or negotiate with other teams to achieve desired resources. While each

15 team can win the competition individually, it is also possible to insert a game

16 element where all teams must produce a solution in order for any individual team

17 to qualify for the competition. This game element can encourage the students to

18 think beyond zero-sum games and to think of winning as a collective effort (win-

19 win). The evidence for the satisfaction in doing so can only emerge at the end of

20 the game, when all the letters are combined to form whole words. Although the

21 current game was designed around the words 'Chemical Engineering', adaptations

22 of the game can be made for other words too. Further permutations of the block

23 may also be applied which could result in different shapes and patterns. For

24 example, Lawson (1979) performed an experiment where different blocks have to

25 be arranged together to meet specific objectives. Thus, the game itself is versatile

26 yet can be easily learnt and played from scratch by inexperienced players

27 including those from non-technical or non-engineering backgrounds.

28 With the three Rounds of the questionnaire administered at different stages of 29 the game, there did not seem to be any major shifts in the opposite direction either

30 from agreement to disagreement or vice versa for all the Statements. A shift was

31 observed for Statement 1 but the degree of shift was relatively low. There were

32 also generally very high counts for agreement even at Round 1 for Statements 1 to

33 3. Furthermore, there was a significant increase in the count for 'Strongly Agree'

34 for all Statements with the exception of Statement 3 comparing Round 1 and 
1 Round 3. These responses suggest that the students became more convinced of

2 their opinions after the game was played. However we cannot say whether the

3 differences were caused by the video and post-game discussion alone or by the

4 combination of playing the game followed by the video and post-game discussion

5 since we did not have a control group.

6 There were generally few differences between the Year 2 and Year 3 students

7 suggesting that prior knowledge of ethics acquired by these students had little

8 impact on their ethical discernment in the game. In terms of the different roles,

9 the game appeared to have an impact on the Engineers while no major differences

10 in the responses collected for the Project Managers and Lead Engineers were

11 observed, possibly due to the small number of samples for the latter roles. In

12 particular, the Engineers recorded a significant increase in 'Strongly Agree' for all

13 Statements after the video and post-game discussion.

14 One reason behind the lack of a larger shift from 'Strongly Agree' to 'Strongly

15 Disagree' for Statement 1 (as expected from Loui's (2006) study) seems to be that

16 the students thought their actions could satisfy both the clients as well as the

17 interests of other stakeholders including the public. The evidence for this is

18 reflected in the high number of teams that attempted to modify their designs, but

19 which led to them failing to meet the original deadline. This observation suggests

20 that the students showed some naivety in understanding the significance of their

21 decisions. It also suggests that the questionnaire may not have captured the

22 completeness of the opinions of the students.

23 Possible improvements to the questionnaire could be made. In one aspect, the

24 strong show of agreement to the Statements may have been a reflection of the

25 response style of the students - specifically they may have a higher tendency to

26 show acquiescence rather than disacquiescence. By including both positive and

27 negative statements (Smith 2003), respondents may need to consider the exact

28 meaning of the question more closely and to increase reflection on initial 29 assertions (Krosnick 1999).

30 In another aspect, the quality of the data may be lowered through the use of 31 multiple questionnaires as a result of declining motivation or an increase in 32 respondent burden (Cannell and Kahn 1968). These effects may result in 33 satisficing, which leads the students to a range of response strategies, including 34 choosing the first response alternative that seems to constitute a reasonable 
1 answer, agree with an assertion made by a question, randomly choosing among

2 the response alternatives offered and giving a NO-opinion (or 'Neutral' as in this

3 study) instead of reporting an opinion (Krosnick 1991). The lack of open-ended

4 comments at the second and third questionnaire suggests that a decrease in

5 motivation may have arisen in the study. However, the response rate remained

6 consistent and the number of 'Neutral' responses remained low in all the

7 questionnaires. Although these observations could also be due to the

8 acquiescence effect as discussed earlier (Krosnick 1999), Sharp and Frankel

9 (1983) found no effect of multiple interviews on increasing respondent burden. In

10 addition, the combined count for neutrality and disagreement remained relatively

11 high throughout all three questionnaires for Statements 4 and 5. These responses

12 suggest that the students were still motivated to complte the questionnaires and

13 their responses to Statements 4 and 5 could be because they had little information

14 or did not fully understand the meaning of the Statements (Krosnick 1999).

15 Although pretesting may not necessarily be practical to implement, careful

16 explanation of the Statements by the facilitators may help to increase the students'

17 understanding of the Statements. The Statements could also be arranged

18 randomly in the questionnaires to avoid order effects (e.g. Schwarz et al. 1992).

19 The random arrangement may also provide a higher number of open-ended

20 comments for Statements 4 and 5 as evidence (e.g. Johnson et al. 1974) suggests

21 that open-ended questions that are at the end of questionnaires obtain fewer

22 responses than those at the beginning of questionnaires.

23 While games which contain ethical elements may increase students' awareness

24 of ethical issues, the games need to be supplemented with other pedagogical

25 methods to increase the depth of learning and help students improve their ethical

26 judgement. For games, an effective post-game discussion is necessary to

27 maximize learning (Bredemeier and Greenblat 1981). However, post-game

28 discussion may only emphasize those parts of reality being simulated by the

29 games (Dorn 1989), or may not be sufficiently general to allow students to learn

30 to handle uncertainties that are associated with many ethical issues. The

31 incorporation of different pedagogical tools, such as different case studies, would

32 most probably be required to allow students to enhance their analytical and critical

33 skills and increase the value of the games experience. 


\section{Conclusions}

2 In this study, a newly-developed game called BLOCKS was conducted as a

3 means of increasing awareness of ethics in engineering. Part of the game includes

4 an ethical scenario which mimics the real-life incident of the Challenger disaster.

5 The significant increase in the count for 'Strongly Agree' for all Statements with

6 the exception of Statement 3 comparing Round 1 and Round 3 suggests that the

7 students became more convinced of their opinions after the game was played.

8 There was little difference in the responses between the Year 2 and Year 3

9 students while the Engineer's role in the game appeared to contribute most to the

10 changes in opinion.

\section{Acknowledgment}

13 We would like to thank Professor Alistair Inglis for proofreading this work.

\section{References}

16 ABET. (2009). Criteria for accrediting engineering programs.

17 http://www.abet.org/Linked\%20Documents-UPDATE/Criteria\%20and\%20PP/E001\%2010-

18 11\%20EAC\%20Criteria\%201-27-10.pdf. Accessed 3 August 2011.

19 Billington, D.P. (2006). Teaching ethics in engineering education through historical analysis.

20 Science and Engineering Ethics, 12, 205-222.

21 Bowyer, K.W. (2001). "Star Wars" revisited - a continuing case study in ethics and safety-critical 22 software. 31th ASEE/IEEE Frontiers in Education Conference, F1D-7.

23 Bredemeier, M. E., \& Greenblat, C. S. (1981). The educational effectiveness of simulation games: 24 a synthesis of findings. Simulation \& Gaming, 12, 307-332.

25 Bucciarelli, L. L. (1999). Design delta design: Seeing/seeing as. In Design thinking research 26 symposium 4, Boston, 23-25 April.

27 Cannell, C.F., \& Kahn, R.L. (1968). Interviewing. In G. Lindzey and E. Aronson (Eds.),The 28 handbook of social psychology, 2: Research method. New York: Addison-Wesley.

29 Chung, C. A., \& Alfred, M. (2009). Design, development and evaluation of an interactive 30 simulator for engineering ethics education (SEEE). Science and Engineering Ethics, 15, 189$31 \quad 199$.

32 Colby, A., \& Sullivan, W. M. (2008). Ethics teaching in undergraduate engineering education. 33 Journal of Engineering Education, 97, 327-338.

34 Cruz, J. A., \& Frey, W. J. (2003). An effective strategy for integrating ethics across the curriculum 35 in engineering: an ABET 2000 challenge. Science and Engineering Ethics, 9, 543-568. 
1 Dorn, D. S. (1989). Simulation games: one more tool on the pedagogical shelf. Teaching 2 Sociology, 17, 1-18

3 Fleddermann, C. B. (2000). Engineering ethics cases for electrical and computer engineering 4 students. IEEE Transactions on Education, 43, 284-287.

5 Haywood, M. E., McMullen, D. A., \& Wygal, D. E. (2004). Using games to enhance student 6 understanding of professional and ethical responsibilities. Issues in Accounting Education, 19, $\begin{array}{ll}7 & 85-99\end{array}$

8 Johnson, W. R, Sieveking, N.A., \& Clanton, E. S. III.(1974). Effects of alternative positioning of 9 open-ended questions in multiple-choice questionnaires. Journal of Applied Psychology, 59, 10 776-778.

11 Kline, R. R. (2001). Using history and sociology to teach engineering ethics. IEEE Technology and Society Magazine, Winter 2001/2002, 13-20.

13 Kroesen, O., \& van der Zwaag, S. (2010). Teaching Ethics to Engineering Students: From Clean

14 Concepts to Dirty Tricks. In I. van de Poel, \& D. E. Goldberg (Eds.), Philosophy and 15 Engineering, Philosophy of Engineering and Technology 2 (pp. 227-237). Netherlands: 16 Springer.

Krosnick, J. A. (1991). Response strategies for coping with the cognitive demands of attitude measures in surveys. Applied Cognitive Psychology, 5, 213-236.

19 Krosnick, J. A. (1999). Survey research. Annual Review of Psychology, 50, 537-56.

20 Kuhn, J. W. (1998). Emotion as well as reason: getting students beyond "interpersonal 21 accountability". Journal of Business Ethics, 17, 295-308.

22 Lawson, B.R. (1979). Cognitive strategies in architectural design. Ergonomics, 22, 59-68.

23 Lewis, S., van Hout, W., \& Huang-Saad, A. (2010). 40 ${ }^{\text {th }}$ ASEE/IEEE Frontiers in Education 24 Conference.S3E-1.

25 Lloyd, P., \& van de Poel I. (2008). Designing games to teach ethics. Science and Engineering 26 Ethics, 14, 433-447

27 Loui, M. C. (2006). Assessment of an engineering ethics video: Incident at Morales. Journal of 28 Engineering Education, 95, 85-91.

29 Pritchard, M. S. (1992). Teaching engineering ethics a case study approach. 30 http://ethics.tamu.edu/pritchar/an-intro.htm. Accessed 3 August 2011.

31 Rabins, M. J. (1998). Teaching engineering ethics to undergraduates: Why? What? How? Science and Engineering Ethics, 4, 291-302.

33 Riley, K., Davis, M., Cox Jackson, A., \& Maciukenas, J. (2009). Ethics in the Details: 34 communicating engineering ethics via micro-insertion. IEEE Transactions on Professional 35 Communication, 52, 95-108.

36 Schwarz, N., Hippler, H. J., \& Noelle-Neumann, E. (1992). A cognitive model of response-order 37 effects in survey measurement. In N. Schwarz, S. Sudman, \& Springer-Verlag (Eds.), Context 38 Effects in Social and Psychological Research. New York.

39 Sharp, L. M., \& Frankel, J. (1983). Respondent burden: A test of some common assumptions. The

Public Opinion Quarterly, 47(1), 36-53. 
1 Smith, T.W. (2003). Developing comparable questions in cross-national surveys. In J. A.

2 Harkness, F. J. R. Van de Vijver, \& P. P. Mohler (Eds.), Cross-Cultural Survey Methods (pp.

3 69-92). New Jersey: Wiley.

4 Van der Burg, S., \& van de Poel I. (2005) Teaching ethics and technology with Agora, an

5 electronic tool. Science and Engineering Ethics, 11, 277-297.

6

\section{$7 \quad$ Footnotes}

$8{ }^{1}$ http://ocw.mit.edu/courses/civil-and-environmental-engineering/1-101-introduction-to-civil-and-

9 environmental-engineering-design-i-fall-2006/delta-game/. Accessed 3 August 2011.

$10{ }^{2}$ http://www.youtube.com/watch?v=j4JOjcDFtBE. Accessed 12 August 2011.

11 